Effect of the variation in the l ower tropospher i c temper at ure on the wi nd onset of the I ndi an summer monsoon

\begin{tabular}{|l|l|}
\hline 著者 & Tani guchi Kenj i , Raj an Devr aj , Koi ke Toshi o \\
\hline $\begin{array}{l}\text { j our nal or } \\
\text { publ i cat i on t i t l e }\end{array}$ & Net eor ol ogy and At nospher i c Physi cs \\
\hline vol une & 106 \\
\hline number & 1 \\
\hline page r ange & $75-94$ \\
\hline year & $2010-01-01$ \\
\hline URL & ht t p: //hdl . handl e. net /2297/20353 \\
\hline
\end{tabular}




\title{
Effect of the Variation in the Lower Tropospheric Temperature on the Wind Onset of the Indian Summer Monsoon
}

\author{
Kenji TANIGUCHI ${ }^{1)}$, Devraj RAJAN ${ }^{2)}$ and Toshio KOIKE ${ }^{3)}$ \\ 1) Faculty of Environmental Design, Kanazawa University, Kanazawa, Japan \\ 2) National Centre for Medium Range Weather Forecasting, Noida, India \\ 3) Department of Civil Engineering, the University of Tokyo, Tokyo, Japan \\ +81-76-234-4629 \\ $+81-76-234-4644$ \\ taniguti@t.kanazawa-u.ac.jp
}

\begin{abstract}
There is a large thermal contrast between the Arabian Peninsula and India $\left(\Delta \theta_{\mathrm{AI}}\right)$ at the mature stage of the Indian summer monsoon (ISM). The forming process of $\Delta \theta_{\mathrm{AI}}$ is investigated analyzing various datasets. It forms earlier in the lower troposphere than in the middle and upper layers. The potential temperature in the lower troposphere over the west coast of India $\left(\theta_{\mathrm{IW}}\right)$ abruptly decreases in advance of the rapid enhancement of the westerly wind over the Arabian Sea corresponding to the ISM onset. Such a process was observed for all the target years and the rapid decrease in $\theta_{\mathrm{IW}}$ could trigger the ISM onset. The decrease in $\theta_{\mathrm{IW}}$ had two patterns. In one case, cooler air is brought by the strong winds around a cyclone over the Arabian Sea. In another case, $\theta_{\text {IW }}$ decreases gradually by a synergy of a southwesterly wind over the Arabian Sea and the enlargement of $\Delta \theta_{\mathrm{AI}}$.
\end{abstract}

Keywords: Indian summer monsoon, wind onset, potential temperature, lower troposphere, cyclone 


\section{Introduction}

Precipitation in India has clear seasonal variation and the onset of the Indian summer monsoon (ISM) is of great interest as not only a scientific research target but also a socioeconomic factor for water resources in India. The onset date of the ISM has been defined by several methods in past studies.

Ananthakrishnan and Soman (1988, hereafter referred to as AS88) defined the ISM onset in the northern and the southern parts of the west coast of India using data from a rain gauge network. The mean seasonal variation in rainfall derived by superimposing the annual onset date showed a distinctly rapid increase in the rainfall representing the beginning of the rainy season. Onset dates defined by rain gauge data correctly reflect the temporal variation in rainfall, however, rainfall is sometimes affected by local variability and large-scale variations are missed. Murakami and Matsumoto (1994) used outgoing long-wave radiation (OLR) to define onset dates of several monsoons in Asia. Those onset dates were derived for a climatological time-series and interannual variability was not discussed.

Simon et al. (2001) focused on the importance of moisture over the Arabian Sea and investigated the total water vapor (TWV) amount during the ISM onset in 2000. A sharp increase in the TWV amount over the western Indian Ocean is recognized about three weeks before the onset of the monsoon. However, drastic change associated with the ISM onset occurs in a much shorter time period and the increase in the TWV amount does not seem to be a trigger of the onset. Ananthakrishnan (1977) suggested that precipitable water content (PWC) alone cannot represent the beginning of the rainy season. In addition to PWC, synoptic and meso-scale disturbances in monsoon circulation leading to low level convergence and vertically ascending flow are required for precipitation to occur. Zeng and Lu (2004) tried to define the climatological onset and withdrawal of the monsoon by PWC at various locations around the globe. Their results represented the difference between the onset and withdrawal season of the monsoon in region to region. In a recent study, Ramesh Kumar et al. (2009) examined various conditions leading to the monsoon onset over Kerala (MOK) using satellite and reanalysis data sets. One interesting feature is the evaporation rates over the southern Arabian Sea and the south Indian Ocean dramatically 
increase one to two pentads before MOK. Though further studies are needed, the result indicates a possible factor to predict early or delayed MOK.

Fasullo and Webster (2003) defined the onset date by vertically integrated moisture transport (VIMT) derived from the National Center for Environmental Prediction and National Center for Atmospheric Research (NCEP/NCAR) reanalysis data. The interannual variation in the onset date modestly agreed with the result of AS88 (correlation coefficient was 0.74); however, they did not discuss a correspondence of the defined onset date and seasonal progression of precipitation. Joseph et al. (2006) investigated onset processes of summer monsoon over South Asia and proposed three-step method for MOK definition. As the first step, the low level westerly over the southern Arabian Sea was used to define MOK. Then the MOK was examined by $850 \mathrm{hPa}$ wind speeds and OLR in the second step. Finally, as the third step, the convective activity around Kerala was checked on the MOK date. In this method, the low level westerly is considered as an important factor to define the ISM onset. Taniguchi and Koike (2006) compared the time-series of satellite-observed PWC and precipitation, and suggested that gradual increasing of the PWC could not be a trigger of the abrupt beginning of ISM rainfall. Taniguchi and Koike (2006) defined the monsoon onset in the northern part of the west coast of India only by wind speed in the lower atmospheric layer over the Arabian Sea. Their definition more properly represented the drastic transition of the atmospheric condition and the beginning of the rainy season in the northern part of the west coast of India than time-series of total water vapor and vertically integrated moisture transportation did. Recently, a new idea of 'wind onset' and 'wind withdrawal' of Asian summer monsoon was provided by Li and Zhang (2009). They focused on the abrupt transition of wind circulation and defined wind onset and withdrawal using the change of wind direction. The definition of ISM onset in Taniguchi and Koike (2006) is a wind onset of the ISM using the wind speed over the Arabian Sea.

At the same time, "bogus onset” is an important aspects of the ISM onset. Fieux and Stommel (1977) and Flateau et al. (2001) introduced the double or bogus onset of the ISM. Sometimes, variables (e.g., wind speed and specific humidity) related to the ISM rapidly increase over a short period and such phenomena are detected as a bogus onset. The definition of the ISM should adequately omit such a bogus onset. The ISM onset defined by Taniguchi and 
Koike (2006) successfully omitted the bogus onset. Their results implied the importance of understanding the formation of the wind field, or monsoon circulation.

Many studies have discussed the mechanism of the abrupt onset of the ISM but still it has not been fully understood. Yin (1949) expounded the ISM onset as northward migration of the equatorial convergence zone (ECZ) accompanied by rapid westward movement of a trough in South Asia at 500hPa. The movement of the trough is due to the northward shift of the mid-latitude westerly jet. Flohn (1957) also discussed the ISM onset from the viewpoint of a large scale circulation pattern and the northward shift of the mid/high-latitude westerly jet. This shift causes northward movement of the intertropical convergence zone (ITCZ) and leads to the onset of the ISM. Joseph et al. (1994) investigated delayed ISM onset. They showed that delayed onset occurs with a delay in the northward movement of the equatorial convective cloudiness maximum (ECCM) accompanied by anomalously high sea surface temperature (SST) south of the equator in the Indian and Pacific Ocean. From these three studies, meridional movement of convective activity caused by the equatorial or tropical convergence zone was thought to be a key factor of the monsoon onset, or the convective activity itself was regarded as the ISM.

Murakami and Ding (1982) studied the seasonal change in the atmospheric field over the Eurasian continent and discussed the relationship with the onset of ISM in 1979. The most significant change is an abrupt increase in temperature and intensification of an anticyclone at $300 \mathrm{hPa}$ in the Afghanistan-western Tibetan Plateau region. However, these changes are recognized two weeks prior to the ISM onset and they might not be a direct trigger of the onset. Krishnamurti and Ramanathan (1982) examined the time evolution of energy exchanges and differential heating around the monsoon onset in 1979. Large increases in the kinetic energy of the total flow field and a non-divergent component of the flow occur over the Arabian Sea just before or about a week prior to the onset of monsoon rains in central India. The above result and Taniguchi and Koike (2006) proved that ISM onset is brought by enhancement of low-level wind over the Arabian Sea.

In this study, we focus on the wind onset of the ISM and examine the seasonal variations in atmospheric fields in detail to understand processes of the 
formation of the monsoon flow. In section 2, the data used in this study are described in detail. In section 3, the climatological seasonal variation in atmospheric fields is investigated and general characteristics around the ISM onset are discussed. In section 4, temporal variations in atmospheric variables associated with the ISM are investigated and their relationships are discussed. In section 5, the seasonal variations in low-level atmospheric fields are investigated in detail for 1998 and 2001, and the causes of the ISM onset are discussed. Finally, the summary and conclusion are given in section 6 .

\section{Data}

To investigate the large scale atmospheric circulation field, reanalysis data from the NCEP/NCAR were used in this study. After 1979, atmospheric sounding data observed by the Television Infrared Observation Satellite (TIROS) Operational Vertical Sounder (TOVS) were used for assimilation and the reanalysis data is thought to be more reliable. We therefore selected 1979-2004 as the target period. The spatial resolution of the reanalysis data is $2.5^{\circ} \times 2.5^{\circ}$ in the horizontal direction and 17 standard pressure levels for the vertical direction. Six hourly, daily, monthly, and climatological values are available from 1948. In this study, daily data were used to investigate the seasonal variation in atmospheric conditions. We used the meridional and zonal wind, geopotential height and air temperature at 850, 500 and 200hPa levels. For details of NCEP/NCAR reanalysis data, see Kalnay et al. (1996).

For precipitation, we used Global Precipitation Climatological Project (GPCP) data. GPCP data is a merged analysis that incorporates precipitation estimates from satellite microwave data, geosynchronous-orbit satellite infrared data and surface rain gauge observations. Monthly average data is available from 1979 to the present, and daily precipitation data is available from 1997 (Huffman et al., 2001). The spatial resolution of monthly and daily data is $2.5^{\circ} \times 2.5^{\circ}$ and $1.0^{\circ} \times 1.0^{\circ}$ respectively. To investigate the seasonal progression in detail, daily data was used in this study.

In addition, to investigate convective activity over the Arabian Sea and the Indian subcontinent, outgoing long-wave radiation (OLR) data from the National 
Oceanic and Atmospheric Agency (NOAA) were also used. Because the original observation has gaps, this data set is filled by temporal and spatial interpolation (Liebmann and Smith, 1996). Daily interpolated OLR data is from twice-daily observations by the advanced very high resolution radiometer (AVHRR) onboard Tiros $\mathrm{N}$ and the NOAA series of satellites. NOAA interpolated OLR data is available from 1981 to the present with a spatial resolution of $2.5^{\circ} \times 2.5^{\circ}$.

For detailed information of cloud activity, Meteosat satellite images from EUMETSAT were referred to this study. These images are obtained from the website of EUMETSAT. On the website, Indian Ocean Data Coverage (IODC) images from 63E are available every three hours. For details, visit the website.

\section{Climatological Seasonal Variations in Atmospheric Fields}

Figures 1 and 2 show climatological (1968-1996 average) pentad-mean characteristics of potential temperature (PT), wind and geopotential height at $850 \mathrm{hPa}, 500 \mathrm{hPa}$ and $200 \mathrm{hPa}$ from spring to early summer. At pentad-16 (average for 17-21 March), the PT is low at 850hPa over a wide region except for the region around $15^{\circ} \mathrm{N}$. The wind is relatively weak, and anticyclonic circulation is recognized over the Arabian Peninsula. At 500hPa, distribution of geopotential height and PT are almost zonally uniform. A westerly wind blows north of $15^{\circ} \mathrm{N}$ line and an easterly wind blows further south. At 200hPa, the PT over the Indian subcontinent and Indonesian maritime continent are lower than over the western part of the Indian Ocean. A uniform westerly wind blows at mid-latitude and the contour of the geopotential height runs from east to west. On the other hand, an easterly wind is observed in the south of $5^{\circ} \mathrm{N}$.

At pentad-22 (average for 16-20 April), still long before the ISM onset, the PT increases over the northern part of the Indian subcontinent, the Middle East and the Arabian Peninsula at 850hPa. The anticyclonic circulation over the Arabian Sea can be still clearly recognized and there is no indication of monsoon circulation. At $500 \mathrm{hPa}$, there is no clear variation in the wind and geopotential height, but an apparent increase in the PT is recognized over the Tibetan Plateau. 
Similar changes can be seen at 200hPa; however, the PT increase occurs not only over the Tibetan Plateau but also over a wide region of India, the Bay of Bengal and the maritime continent.

At pentad-26 (average for 06-10 May), the anticyclonic circulation over the Arabian Peninsula and the Arabian Sea can sitll be observed; however a variation in the geopotential height indicates the atmospheric pressure in lower layers is less than that at pentad-22. Because of the land surface heating, a low pressure region spreads over the Indian subcontinent and the western part of the Bay of Bengal. At 500hPa, a distinct anticyclonic circulation forms over the edge of the Arabian Peninsula. A warm region spreads northward especially over around the Tibetan Plateau. The spread of the warmer region is also observed at 200hPa, but its center is placed in more westward. An area with dense contour intervals of geopotential height moves northward, and strong westerly winds also moves northward.

At pentad-33 (average for 10-14 June), strong westerly winds have already blown onto the whole of the west coast of the Indian subcontinent at $850 \mathrm{hPa}$. The distribution of the PT shows a warm region over the Arabian Peninsula and the Iran-Pakistan area and a cold region from the Indian Ocean to the southern tip of the Indian subcontinent. There is a large PT gradient between the Arabian Peninsula and the region from the southern part of the Arabian Sea to the western tip of the Indian subcontinent. An anticyclonic circulation spreads from the Arabian Peninsula to southwestern China at $200 \mathrm{hPa}$, and a low pressure field spreads from the Arabian Sea to the Bay of Bengal at 500hPa; however, there is no significantly warm or cold region in both layers in the shown domain.

The distribution of wind, PT and geopotential height at $850 \mathrm{hPa}$ at pentad35 is similar to that at pentad-33. There is a significant thermal gradient between the Arabian Peninsula and the west coast of the Indian subcontinent. Monsoon circulation is often referred to as a flow generated by the large scale thermal contrast between land (Eurasian continent) and ocean (the Indian Ocean); however, the strong westerly and southwesterly winds over the Arabian Sea could be caused by the smaller scale thermal contrast between the Arabian Peninsula and the west coast of the Indian subcontinent. At 500hPa and $200 \mathrm{hPa}$, the distribution of PT and geopotential height at pentad-35 is also similar to that at pentad-33. The increase of PT is observed around the tip of the Bay of Bengal; 
however, the temperature gradient at $500 \mathrm{hPa}$ is not as large as that in the lower layer. At $200 \mathrm{hPa}$, there is a warm region to the west of the Tibetan Plateau and cold region over the western equatorial Indian Ocean; however, there is great distance between them and the temperature gradient between them is less than that in the lower level.

At pentad-39 (average for 10-14 July), considered to be a mature stage of the ISM, the wind and geopotential height are not so different from those at pentad-35. At 850hPa, the distribution of PT is also similar to that in the previous period. At $500 \mathrm{hPa}$ and $200 \mathrm{hPa}$, a warmer region spreads over land. The air over the eastern part of the Indian Ocean becomes colder at 200hPa. Though atmospheric conditions at $850 \mathrm{hPa}$ do not change significantly, the PT distribution at $500 \mathrm{hPa}$ and $200 \mathrm{hPa}$ clearly vary with seasonal progression, or maturation of the summer monsoon. These results indicate the ISM circulation is firstly formed in the lower troposphere, and then, atmospheric conditions in the upper layer are affected by the development of the ISM.

Pearce and Mohanty (1984) examined the onset of the Asian summer monsoon from 1979 to 1982 and showed the progressive development of the mean low-level monsoon flow over the Arabian Sea without a corresponding mean flow development in the upper level. Joseph et al. (1994) showed the seven year mean wind at $150 \mathrm{hPa}$ and the subtropical jet stream flowing south of the Himalaya weaken at the ISM onset and the core of the jet shifted two pentad periods later than the ISM onset. They explained the change in the upper layer is in response to the tropospheric heating by the low-level monsoon current. Ramesh et al. (1996) showed a time series of moisture, temperature and kinetic energy over the Arabian Sea and suggested the low-level flow and reverse flow at 150hPa strengthens owing to the increase in latent heat release associated with the onset of the summer monsoon over the southern tip of India. Joseph et al. (2006) investigated a temporal variation of vertical profile of zonal wind over the Arabian Sea and showed the westerly firstly enhances at lower layer before MOK, then develops in the middle of troposphere at MOK.

From the above studies and the results shown in Fig.2, it is suggested the low-level monsoon flow forms prior to the reverse flow in the upper layer. In the seasonal progression of the ISM, convective activity strengthens first owing to the ISM onset, and then the increasing latent heat release in the upper layer enhances 
the reverse flow in the upper layer. Finally, large scale monsoon circulation, including both upper and lower layers, is completed.

Joseph et al. (1994) compared the distributions of the SST for early and delayed onset cases. In the cases of early onset, a positive SST anomaly spread in the northern part of the Arabian Sea and a negative SST anomaly spread to the south of the Arabian Sea. The opposite distribution of the SST was observed in the delayed cases. The SST is supposed to affect the change in the lower air temperature; thus, the air temperature in the lower layer is thought to have a similar distribution. Therefore, the results by Joseph et al. (1994) indicate the thermal contrast in the lower troposphere over the Arabian Sea has an important role in the ISM onset, and the atmospheric condition in the lower troposphere is more directly related to the ISM onset.

Based on the above results from this study and the retrospective studies, regarding the ISM onset, we focus on the formation of the low level monsoon current over the Arabian Sea and examine the seasonal progression of atmospheric conditions in the next section.

\section{Time variations in Atmospheric Conditions around the Arabian Sea}

From Figs. 1 and 2, we speculate the strong monsoon westerly wind over the Arabian Sea can be generated by the temperature gradient between the Arabian Peninsula and the western part of the Indian subcontinent at $850 \mathrm{hPa}$. A time-series of the PT gradient between those two regions $\left(\Delta \theta_{\mathrm{AI}}\right)$, the wind speed over the Arabian Sea $\left(|\mathbf{U}|_{A}\right)$, the precipitation in the northern part of the west coast of India $\left(P R_{\mathrm{IW}}\right)$, potential temperature over the Arabian Peninsula $\left(\theta_{\mathrm{A}}\right)$ and the PT in the western part of India $\left(\theta_{\mathrm{IW}}\right)$ from 1997 to 2004 are investigated. $\Delta \theta_{\mathrm{AI}}$ is defined as the difference in $\theta_{\mathrm{A}}\left(45^{\circ} \quad \mathrm{E}-62.5^{\circ}\right.$ E, $\left.20^{\circ} \mathrm{N}-27.5^{\circ} \mathrm{N}\right)$ and $\theta_{\mathrm{IW}}\left(70^{\circ}\right.$ E-77. $5^{\circ}$ E, $\left.10^{\circ} \mathrm{N}-20^{\circ} \mathrm{N}\right) .|\mathbf{U}|_{\mathrm{A}}$ and $P R_{\mathrm{IW}}$ are averaged in $\left(62.5^{\circ} \quad \mathrm{E}-75^{\circ} \mathrm{E}\right.$, $\left.7.5^{\circ} \mathrm{N}-20^{\circ} \mathrm{N}\right)$ and $\left(70^{\circ} \mathrm{E}-75^{\circ} \mathrm{E}, 15^{\circ} \mathrm{N}-22.5^{\circ} \mathrm{N}\right)$ respectively. The grid boxes of those variables are shown in Fig. 3. The averaging box for $\theta_{\mathrm{IW}}\left(\theta_{\mathrm{A}}\right)$ is selected as the area in which the significant cooling (warming) is detected (Figs. 1 
and 2). For $|\mathbf{U}|_{\mathrm{A}}$ and $P R_{\mathrm{IW}}$, those areas are selected in which the wind at $850 \mathrm{hPa}$ significantly enhances and heavy rainfall occurs during ISM period, respectively (originally defined in Taniguchi and Koike 2006). $\Delta \theta_{\mathrm{AI}},|\mathbf{U}|_{\mathrm{A}}, \theta_{\mathrm{IW}}$ and $\theta_{\mathrm{A}}$ were computed by using NCEP/NCAR reanalysis data at $850 \mathrm{hPa}$, and $P R_{\mathrm{IW}}$ is defined by GPCP rainfall data. Figure 4 shows the time-series of $\Delta \theta_{\mathrm{AI}},|\mathbf{U}|_{\mathrm{A}}, \theta_{\mathrm{IW}}, \theta_{\mathrm{A}}$ and $P R_{\mathrm{IW}}$. At the same time, the onset date of the ISM in each target year defined in Taniguchi and Koike (2006) is indicated by the upward arrow in Fig. 4. Hereafter, those onset dates are considered as the wind onset of the ISM and the dates of the formation of the Indian monsoon circulation.

As shown in Taniguchi and Koike (2006), rapid enhancement of $|\mathbf{U}|_{\mathrm{A}}$ and the abrupt beginning of rainy season in India occur simultaneously. $\Delta \theta_{\mathrm{AI}}$ is formed by the increasing in the PT over the Arabian Peninsula and the decrease over the west coast of the Indian subcontinent. $\Delta \theta_{\mathrm{AI}}$ begins to increase from early spring and becomes greater than $9 \sim 10 \mathrm{~K}$ in the transition period, or the beginning of rainy season and during the rapid enhancement of $|\mathbf{U}|_{\mathrm{A}}$. However, $\Delta \theta_{\mathrm{AI}}$ does not change as drastically as $|\mathbf{U}|_{\mathrm{A}}$ and $P R_{\mathrm{IW}}$ do. The PT over the Arabian Peninsula $\left(\theta_{\mathrm{A}}\right)$ does not abruptly change either. On the other hand, there is a clear and more rapid variation in $\theta_{\mathrm{IW}}$ during the transition period of $|\mathbf{U}|_{\mathrm{A}}$ and $P R_{\mathrm{IW}}$. The start of the decrease in $\theta_{\mathrm{IW}}$ is prior to the enhancement of the westerly wind and the beginning of the rainy season in all years from 1997 to 2004. These results suggest the decrease in $\theta_{\mathrm{IW}}$ could trigger the ISM onset. This rapid decrease in $\theta_{\mathrm{IW}}$ is thought to be an important factor in the form of the PT gradient, which drives the strong westerly wind over the Arabian Sea.

In 2004, there is significant precipitation and a clear decrease in $\theta_{\mathrm{IW}}$ in early May. However, $|\mathbf{U}|_{\mathrm{A}}$ is not strong enough and $\theta_{\mathrm{IW}}$ increases again just after the rainfall. Figure 5 shows a cloud cluster moves northward to India in the period of this first rainfall in 2004 and it is supposed to be a cause of the rainfall. On the other hand, $\Delta \theta_{\mathrm{AI}}$ is less than for other years and $|\mathbf{U}|_{\mathrm{A}}$ is not enhanced (Fig. 4) during this rainfall. This small $\Delta \theta_{\mathrm{AI}}$ is caused by the lower PT over the Arabian Peninsula even though $\theta_{\mathrm{IW}}$ decreases. The above results indicate the first rainfall in 2004 is not necessarily associated with the ISM onset. Joseph and Pillai (1988) investigated the pre-onset monsoon rainfall peak (PMRP), and the early rainfall in 2004 is supposed to be one example of PMRP. 
Some studies have discussed the atmospheric temperature and heating around the Arabian Sea in the period of the ISM onset. Mohanty et al. (1983), Pearce and Mohanty (1984) and Ramesh et al. (1996) investigated the atmospheric temperature averaged over the 1000-100hPa layer. Their results showed an increasing of the mean atmospheric temperature over the Arabian Sea is related to the ISM onset. However, the PT at $850 \mathrm{hPa}$ clearly decreases before the rapid enhancement of $|\mathbf{U}|_{\mathrm{A}}$ (or ISM onset) as shown in Fig. 4. Thus, upper and lower layers should be treated separately because the cooling of the lower troposphere in western India is supposed to be an important factor in the form of large $\Delta \theta_{\mathrm{AI}}$ driving the strong westerly wind over the Arabian Sea, or the low-level circulation of the ISM. The heating over the Arabian Peninsula is thought to be caused by the seasonal change in the sun altitude. On the other hand, the cooling process of the Indian subcontinent is unclear. In the next section, focusing on the decrease in $\theta_{\mathrm{IW}}$, temporal variation in low-level atmospheric conditions will be examined in detail.

\section{Detail Investigation into the Seasonal Variation in the Low Level Atmospheric Field}

Using NCEP/NCAR reanalysis data, daily based temporal variations in low-level atmospheric fields were investigated from 1979 to 2004. Spatial distribution of potential temperature and geopotential height at $850 \mathrm{hPa}$ showed two patterns of atmospheric cooling over the Indian subcontinent and ISM onset in these 26 years. In one case, $\theta_{\mathrm{IW}}$ decreases rapidly owing to a cyclonic vortex circulation over the Arabian Sea, or the Bay of Bengal. In another case, a cyclonic vortex was not recognized in that region while $\theta_{\mathrm{IW}}$ decreases. The atmospheric field changes gradually and the ISM begins (hereafter "non-cyclone-caused" onset). In this paper, a cyclone is visually defined by close contours of geopotential height (the region with minimum geopotential height) accompanied by strong wind and precipitation. To determine the existence of precipitation, GPCP data were used for 1997-2004 and NOAA OLR data for 1979-1996. In Table.1, the onset date and cause of the variation in the atmospheric field are summarized. Onset dates were defined by the method of Taniguchi and Koike 
(2006). In more than half of the target years, atmospheric conditions around the Arabian Sea were affected by cyclones. In the following subsections, the cases of 1998 and 2001 are presented as cyclone-caused and noncyclone-caused onsets.

\subsection{Case of 1998 (cyclone-caused onset)}

In 1998, the distribution of PT at $850 \mathrm{hPa}$ rapidly changes owing to a cyclonic vortex and the ISM begins immediately after. Figure 6 shows the seasonal progression of the distribution of the PT, wind and geopotential height at 850hPa in 1998. On 1 June, the wind is weak and its direction is unclear over the Arabian Sea. Regarding the distribution of the PT, the warmer air is spread over the Arabian Peninsula, Middle East and the Indian subcontinent. From Iran and Pakistan to India, there is a low pressure field caused by the warm air. Especially over the Indian subcontinent, a strong thermal low is recognized. On 2 June, though there is no remarkable change in the atmospheric field, there is a decrease in the geopotential height at $850 \mathrm{hPa}$ over the Arabian Sea around $60^{\circ}$ E, $15^{\circ} \mathrm{N}$. This decrease becomes a small low-pressure system on 3 June, and the low begins to move eastward. At the same time, a cyclonic circulation can be seen around the low. This low grows up and moves eastward, then crosses the Arabian Sea between 4 and 6 June. The wind around the low becomes stronger during this period. Focusing on the distribution of potential temperature, a contour of 308K indicates that, owing to the strong wind in the southeast of the low, a cooler air mass flows onto the southern tip of the Indian subcontinent from above the southern part of the Arabian Sea. On 7 June, the cyclonic low heads northward along the west coast of the Indian subcontinent and a cooler region spreads over the subcontinent. The wind becomes strong with the development of the cyclonic low and a southwesterly wind downstream of the Somali Jet is recognized over the Arabian Sea. Here, the distribution of the PT at $850 \mathrm{hPa}$ is similar to that in the mature period of the ISM shown in Fig. 2. A strong southwesterly wind forms over the entire Arabian Sea and a strong westerly wind blows onto the Indian subcontinent on 9 June. Even after the disappearance of the low, the distribution of the PT remains similar to that in the mature stage of the ISM, and the strong southwesterly and westerly wind continue to blow over the Arabian Sea.

Figure 7 shows the GPCP daily precipitation and geopotential height at 850hPa from NCEP/NCAR reanalysis. In the south of India, precipitation can be 
seen before the generation of the low (1 June). There is no strong monsoon westerly wind over the Arabian Sea and the Indian subcontinent; however, a westerly wind blows on the southern tip of India and cause precipitation before the wind onset of the ISM. Past studies (e.g., Ananthakrishnan and Soman (1988) and Taniguchi and Koike (2006)) showed the beginning of rainfall is earlier in the south than in the north in India. This southern India rainfall before the enhancement of strong westerly wind over the Arabian Sea might be defined as pre-onset Indian rainfall as introduced by Joseph and Pillai (1988). The temporal variation in precipitation and geopotential height in Fig. 7 shows the low generated in the coastal area of the Arabian Peninsula on 2 or 3 June. The low increases in area with precipitation after crossing the Arabian Sea, and then the low moves northward associated with the precipitation. Figure 8 is the visible channel satellite image provided by EUMETSAT from 5 to 10 June. On 5 June, a distinctive cloud region can be recognized in the west of the tip of India. The satellite images and geopotential height in Fig. 6 show the strong cyclone developed in the Arabian Sea. Satellite images in Fig. 8 show the cyclone moving northward along the west coast of the Indian subcontinent. In the above discussion, the strong southwesterly wind around the cyclone transports cooler air mass above the ocean onto the land. At the same time, strong cloud activity associated with the cyclone is thought to intercept shortwave radiation from the sun and promotes a decrease in PT over the Indian subcontinent. In addition, precipitation from the cyclone changes the land surface condition from dry to wet, and an increasing in evaporation from the surface can cause atmospheric cooling in the lower atmospheric layer through the absorption of latent heat. The time series of the wind speed and rainfall in Fig. 4 shows a rapid transition of atmospheric conditions and continuance of strong wind and rainfall after the onset date (7 June).

In 1998, the cyclone moves eastward. In some cases of cyclone-caused onset, a cyclone develops in the Arabian Sea and does not move, but remains in the region of cyclogenesis. Even in such cases, strong wind around a cyclone transports cooler air mass from the southern part of the Arabian Sea to the west coast of India and leads to the ISM onset. In 1991 and 1999, cyclones form and develop in the Bay of Bengal, and move westward to India. These cyclones also lead to the ISM onset. The developments of cyclone are more often recognized in 
the Bay of Bengal than in the Arabian Sea. But all of those cyclones do not necessarily cause the ISM onset.

\subsection{Case of 2001 (non-cyclone-caused onset)}

Figure 9 is the same as Fig. 6 but for 2001. On 2 May, a warm region spreads from the Arabian Peninsula to the Indian subcontinent. A high pressure region is recognized over the Arabian Peninsula and there is a wind blowing northeasterly, which is exactly opposite to the monsoon circulation, over the Arabian Sea. This anticyclone disappears between 4 and 6 May and a weak southwesterly wind forms along the Arabian Peninsula. Comparing the PT distribution between 6 and 1 May, the PT over the ocean decreases along the coast of the Arabian Peninsula. This is possibly because the southerly wind in this region brings colder air mass northward from the ocean to the land. From 7 to 10 May, spreading of the cooler area is recognized at the western base of the Indian subcontinent. During this period, the weak southwesterly wind blows along the coastal line of the Arabian Peninsula and slowly brings cooler air to the Arabian Sea. On 10 May, the southwesterly wind blows across the almost entire Arabian Sea. This southwesterly wind is supposed to form owing to the thermal contrast between the peninsula and the Arabian Sea. The wind then possibly brings cooler air from the sea region again. From 11 to 13 May, warm air remains over the Indian subcontinent and a thermal low disturbs the formation of the monsoon westerly wind. From 14 May, the PT increases over the Arabian Peninsula and Middle East, and the PT contour interval becomes small. On 19 or 20 May, the PT over the western part of the Indian subcontinent obviously decreases, and a clear thermal contrast forms between the Arabian Peninsula and the west coast of India. Along the contours of the PT, a westerly wind forms over the ocean and blows onto India. As the temperature gradient becomes large, the southwesterly and westerly winds over the Arabian Sea becomes strong (16 and 17 May), and the PT over the Indian subcontinent falls. In Fig. 4, the rapid decrease in PT is recognized in the middle of May, just before the onset of the ISM (23 May).

In the above discussion, the variation in the PT distribution or spreading of the cooler region is explained as the result of horizontal advection. In the case of 1998, the effect of cloud associated with the cyclone was described. Figure 10 shows the temporal variations in $|\mathbf{U}|_{\mathrm{A}}, \theta_{\mathrm{IW}}$, and OLR over the west coast of India 
$\left(10^{\circ} \mathrm{N}-20^{\circ} \mathrm{N}, 70^{\circ} \mathrm{E}-77.5^{\circ} \mathrm{E}\right)$. OLR is often used as an index of convective activity in tropical regions and a small OLR value represents active convection. An abrupt decrease in OLR after mid-May and the continuance of small OLR represent the beginning of the rainy season. The increasing OLR just after midMay indicates a break of the ISM as recognized in Fig. 3. The decrease in OLR occurs later than does the decrease in $\theta_{\mathrm{IW}}$. At the same time, the rapid enhancement of $|\mathbf{U}|_{\mathrm{A}}$ occurs in advance of the decrease in OLR. Figure 11 is the visible channel images observed by METEOSAT. There is not clear or strong cloud activity over the western part of the Indian subcontinent even in the period of the PT decreasing. The above results indicate the decrease in $\theta_{\mathrm{IW}}$ in 2001 is not necessarily caused by the rainfall and interception of shortwave radiation by cloud activity, and the enhancement of $|\mathbf{U}|_{\mathrm{A}}$ by the decreasing $\theta_{\mathrm{IW}}$ leads to the beginning of the ISM. Therefore, the decrease in $\theta_{\mathrm{IW}}$ is a possible trigger of the ISM onset.

Figure 12 is the same as Fig. 10 but for other years of non-cyclone-caused ISM onset. In 1979, 1980, and 1981, OLR decreased in advance of that of $\theta_{\mathrm{IW}}$. On the contrary, the decrease in $\theta_{\mathrm{IW}}$ is earlier than that of OLR in 1989, and 2000. In the other five years, the decreases occur at the same time. These comparisons of the time-series of the PT and OLR give rise to speculation that cloud activity on the west coast of India does not necessarily affect the rapid and significant decrease in the PT. In the case of a gradual onset like that in 2001, atmospheric advection is supposed to be one possible cause of the variation in the atmospheric condition leading to the ISM onset.

From Ninomiya and Akiyama (1976), the local rate of temperature change averaged over a certain area is expressed as

$$
\frac{\partial \bar{T}}{\partial t}=\frac{d T}{d t}-\bar{v} \cdot \overline{\nabla T}-\left[\bar{\omega}^{*}+\frac{\partial \bar{T}}{\partial p^{*}}+\frac{R}{C_{p}} \frac{\bar{T}}{p}\left(\bar{\omega}^{*}-\bar{\omega}_{0}\right)\right]
$$

where $d T / d t$ represents diabatic heating, $\bar{v} \cdot \overline{\nabla T}$ represents advection, and the remainder is the adiabatic temperature change due to vertical motion. Here, the diabatic heating is described by

$$
\frac{d T}{d t}=\frac{d T_{R}}{d t}+\frac{L}{C_{p}} m-\frac{\partial\left(\overline{\omega^{*} T^{\prime}}\right)}{\partial p^{*}}
$$


where $d T_{R} / d t, L / C_{p} \cdot m$, and $-\partial\left(\overline{\omega^{*} T^{\prime}}\right) / \partial p^{*}$ represent heating due to radiation, condensation, and vertical convergence of convective heat transport respectively. In this study, we focus on the effect of horizontal advection on the rapid decrease in PT on the western coast of India and investigate $-\bar{v} \cdot \overline{\nabla T}$.

Figure 13 is the horizontal distribution of the advection term $(-v \cdot \nabla T)$ of $\partial \bar{T} / \partial t$ and daily variation of air temperature at $850 \mathrm{hPa}$ during the period before the ISM onset (from 1 May to 21 May) in 2001.

On 1 May, there is not significant decreasing PT in western India and no clear tendency of the spatial distribution of the advection term. On 7 May, a significant decreasing PT and a negative value of the advection term are observed around the west base of the Indian subcontinent. Figure 9 shows a clear decrease in PT in the same region around 7 May. A minimum value is seen just over the west coast of the Indian subcontinent. A similar spatial distribution of the advection is recognized on 14 May. A clear and significant decrease in the PT in western India is recognized after 10 May in Fig. 4. These results show the cooling in northwestern India is caused by horizontal incursion of cooler air-mass from the ocean southward associated with the horizontal advection. Around the head of the Arabian Sea, a large positive value is observed on 14 and 21 May. This is because of the large temperature difference between the land and ocean, and southward and eastward flows bring warmer air mass from over the land to the ocean (see Fig. 9). On 21 May, just before the ISM onset in 2001, there is still a large negative value of the advection term and a decreasing PT in India. Such a continuous inflow of cooler air mass seems to be an important factor in decreasing the PT in that region.

After the ISM onset, cooler air mass flows onto the Indian subcontinent owing to the monsoon westerly wind and it may maintain the temperature gradient between the Arabian Peninsula and western India, which drives the monsoon westerly wind.

In most non-cyclone-caused ISM onset cases, a negative value of the horizontal advection, or PT decreasing owing to incursion of cooler air mass, is observed. However, the magnitude of the advection term is not always the same and the time of the appearance of the negative value has some fluctuation. In some 
cases, such a feature of the advection term is not clear. To understand the noncyclone-caused ISM onset, in-depth analysis is indispensable for each case.

\subsection{Difference between cyclone-caused and non-cyclone-caused onset}

Figures 14a and 14b are composites of PT, wind and geopotential height for the onset date of cyclone-caused and non-cyclone-caused onset cases. In the case of the cyclone-caused onset, a cyclonic anomaly is clearly recognized in the Arabian Sea but not in the case of the non-cyclone-caused onset. Figure 14c is the difference of those results calculated by subtracting the non-cyclone-caused composite from the cyclone-caused one. Anomalies of northward flow and low temperature over the Arabian Sea indicate the strong wind around a cyclone brings colder air from southern part and decreases PT effectively in cyclonecaused onsets. Fig. 14c also shows a clear anti-cyclonic anomaly in the Bay of Bengal. This result indicates, in the non-cyclone-caused onset, ISM onset occurs after development of low pressure field in the Bay of Bengal, or in the mature stage of the monsoon in this region. On the other hand, the cyclone-caused onset could occur before such a maturation of monsoon in the Bay of Bengal.

\section{Summary and Conclusions}

In this paper, the wind onset of the ISM was discussed and, to reveal processes of the formation of the low-level monsoon circulation, the seasonal variations in atmospheric characteristics in the lower troposphere were investigated in detail. Climatological characteristics of various atmospheric fields showed the PT gradient is large in the lower layer between the Arabian Peninsula and the west coast of the Indian subcontinent. Such a PT distribution, or the temperature gradient between them, possibly produces the strong westerly wind over the Arabian Sea, which brings rainfall in India during the active season of the ISM. Though the rainy season in India begins quite abruptly, this temperature gradient does not have a clear rapid variation. On the other hand, the seasonal variation in the PT over the west coast of India rapidly decreases just before the abrupt beginning of the rainy season, or the ISM onset. This feature was observed 
for every year, and hence, the decrease in PT is a possible trigger of the formation of the strong monsoon westerly wind, or the ISM onset.

Detailed studies of the seasonal progression of atmospheric fields for the target years show the decreasing in PT is caused by two processes: (i) a strong cyclone generating atmospheric cooling by horizontal advection with strong wind, interception of shortwave radiation, and latent heat absorption accompanied by evaporation of rainfall and (ii) the PT gradient completing gradually and not being affected by a specific event like a cyclone. From 1979 to 2004, the decrease in PT, or ISM onset, is brought about by a cyclone in 15 of the years. Most of these cyclones formed and developed in the Arabian Sea; however, some were formed in the Bay of Bengal. To understand the monsoon system, the formation and development of the cyclone around the Arabian Sea is also important. In the other case, the variation in the PT distribution is not caused by a cyclone, and horizontal advection is supposed to play an important role. However, the effects of other factors (e.g., SST, soil moisture, larger scale circulation) have to be investigated in more detail.

In future study, the above issues should be investigated more quantitatively with numerical simulations using regional circulation models and integration of various kinds of observation data and model outputs from numerical weather prediction centers.

Acknowledgements: The authors are grateful for the use of NCEP/NCAR reanalysis data provided by the NOAA-CIRES Climate Diagnostic Center, GPCP daily precipitation data provided by the NASA/Goddard Space Flight Center's Laboratory for Atmosphere, interpolated OLR data provided by the NOAA/OAR/ESRL PSD, and the Meteosat-5 images provided by EUMETSAT. The authors also would like to thank the anonymous reviewers for providing helpful suggestions on an earlier version of the manuscript.

\section{References:}

Ananthakrishnan R (1977) Some aspects of monsoon circulation and monsoon rainfall. Pure and Appl Geophys 115:1209-1249

Ananthakrishnan R, Soman MK (1988) The onset of the southwest monsoon over Kerala. J

Climatol 8:283-296 
Fasullo J, Webster PJ (2003) A hydrological definition of Indian monsoon onset and withdrawal. J Clim 16:3200-3211

Fieux M, Stommel H (1977) Onset of southwest monsoon over Arabian sea from marine reports of surface wind-structure and variability. Mon Wea Rev 105:231-236

Flateau MK, FlateauPJ, Rudnick D (2001) The dynamics of double monsoon onsets. J Clim 14:4130-4146.

Flohn H (1957) Large-scale aspects of the "Summer Monsoon” in south and east Asia. J Meteorol Soc Jpn 75th Anniversary volume:180-186

Huffman GJ, Adler RF, Morrissey M, Bolvin DT, Curtis S, Joyce R, McGavock B, Susskind J (2001) Global precipitation at one-degree daily resolution from multi-satellite observations. J Hydrometeorol 2:36-50 Joseph PV, Pillai PV (1988) 40-day mode of equatorial trough for long-range forecast of Indian summer monsoon onset. Curr Sci 57:951-954

Joseph PV, Eischeid JK, Pyle RJ (1994) Interannual variability of the Onset of the Indian summer monsoon and its association with atmospheric features, El Nino, and sea surface temperature anomaly. J Climate, 7:81-105

Joseph PV, Soorj KP, Rajan CK (2006) The summer monsoon onset process over south Asia and an objective method for the date of monsoon onset over Kerala. Int J Climatol 26:1871-1893 Krishnamurti TN Ramanathan Y (1982) Sensitivity of the monsoon onset to differential heating. J Atmos Sci 39:1290-1306

Li J, Zhang L (2009) Wind onset and withdrawal of Asian summer monsoon and their simulated performance in AMIP models. Clim Dyn 32:935-968

Liebmann B, Smith CA (1996) Description of a complete (interpolated) outgoing longwave radiation dataset. Bull Am Meteorol Soc 77:1275-1277

Mohanty UC, Dube SK Singh MP (1983) A study of heat and moisture budget over the Arabian sea and their role in the onset and maintenance of summer monsoon. J Meteorol Soc Jpn 61:208221

Murakami T, Ding YH (1982) Wind and temperature changes over the Eurasia during the early summer of 1979. J Meteorol Soc Jpn 60:183-196

Murakami T, Matsumoto J (1994) Summer Monsoon over the Asian Continent and Western North Pacific. J Meteorol Soc Jpn 72:719-745

Ninomiya K, Akiyama T (1976) Structure and Heat Energy Budjet of Mixed Layer Capped by Inversion during the Period of Polar Outbreak over Kuroshio Region. J Meteorol Soc Jpn 54:160174

Pearce RP, Mohanty UC (1984) Onsets of the Asian summer monsoon 1979-82. J Atmos Sci 41:1620-1639

Ramesh KJ, Basu S, Begum ZN (1996) Objective determination of onset, advancement and withdrawal of the summer monsoon using large-scale forecast fields of a global spectral model over India. Meteorol Atmos Phys 61:137-151

Ramesh Kumar MR, Sankar S, Reason C (2009) An investigation into the condition leading to monsoon onset over Kerala. Theor Appl Climatol, 95:69-82 
Simon B., Joshi PC, Thapliyal PK, Pal PL, Sarkar A, Bhatia RC, Jain RL, Singh D, Mukherjee SK, Gupta HV (2001) Monsoon onset-2000 monitored using multifrequency microwave radiometer on-board Oceansat-1. Curr Sci, 81:647-651

Taniguchi K, Koike T (2006) Comparison of definitions of Indian summer monsoon onset: Better representation of rapid transitions of atmospheric conditions. Geophys Res Lett, 33:L02709.

doi:10.1029/2005GL024526

Yin MT (1949) A synoptic-aerologic study of the onset of the summer monsoon over the India and Burma. J Atmos Sci 6:393-400

Zeng X, Lu E (2004) Globally unified monsoon onset and retreat indexes. J Climate 17:2241-2248 EUMETSAT (2007) EUMETSAT High Resolution Image - the Indian Ocean Data Coverage, http://www.eumetsat.int/Home/Main/Access_to_Data/Meteosat_Image_Services/SP_1119363946 419. Accessed 20 Apr 2007 
Figure 1: Climatological seasonal progression of pentad-mean potential temperature, wind and geopotential height. Upper, middle and lower panels show the results for $850 \mathrm{hPa}, 500 \mathrm{hPa}$ and 200hPa respectively. NCEP/NCAR reanalysis data is used. Areas with altitude greater than 1500 m are shaded black. Results are shown for pentad 16, 22 and 26 (P16, P22 and P26, respectively).

Figure 2: Climatological seasonal progression of pentad-mean potential temperature, wind and geopotential height. Upper, middle and lower panels show the results for $850 \mathrm{hPa}, 500 \mathrm{hPa}$ and 200hPa respectively. NCEP/NCAR reanalysis data is used. Areas with altitude greater than 1500 m are shaded black. Results are shown for pentad 33, 35 and 39 (P33, P35 and P39, respectively).

Figure 3: Boxes used to define the spatial averaged variables. Boxes indicated A, B, C and D are used for potential temperature over the Arabian Peninsula $\left(\theta_{\mathrm{A}}\right)$, wind speed over the Arabian Sea $\left(|\mathbf{U}|_{\mathrm{A}}\right)$, potential temperature over the west coast of India $\left(\theta_{\mathrm{IW}}\right)$ and precipitation in the northern part of India $\left(P R_{\mathrm{IW}}\right)$, respectively. Boxes $\mathrm{A}$ and $\mathrm{C}$ are used to define difference between $\theta_{\mathrm{A}}$ and $\theta_{\mathrm{IW}}$ $(\Delta \theta)$.

Figure 4: Time-series of precipitation in the northern part of India $\left(P R_{\mathrm{IW}}\right)$, potential temperature over the Arabian Peninsula $\left(\theta_{\mathrm{A}}\right)$ and the west coast of India $\left(\theta_{\mathrm{IW}}\right)$, wind speed over the Arabian Sea $\left(|\mathbf{U}|_{\mathrm{A}}\right)$ and difference between $\theta_{\mathrm{A}}$ and $\theta_{\mathrm{IW}}(\Delta \theta)$. The onset date of the ISM in each year is indicated by an upward pointing arrow. Results are shown for 1997-2004.

Figure 5: Visible channel images of Meteosat for the period around the onset of the ISM in 2004.

Figure 6: Temporal variation in the potential temperature, wind and geopotential height at 850hPa in 1998. NCEP/NCAR reanalysis data are used. Contour lines and shade colors indicate geopotential height and potential temperature, respectively. The thick and dotted line indicates the isoline of 308K. Areas with altitude greater than $1500 \mathrm{~m}$ are shaded black.

Figure 7: Temporal variation in the precipitation and geopotential height during the same period as for Fig.6. GPCP data are used to plot the distribution of the precipitation. Contour lines and shade colors indicate geopotential height and precipitation, respectively. Areas with altitude greater than $1500 \mathrm{~m}$ are shaded black.

Figure 8: Visible channel images of Meteosat for the period around the onset of the ISM in 1998.

Figure 9: Temporal variation in the potential temperature, wind and geopotential height at 850hPa in 2001. NCEP/NCAR reanalysis data are used. Contour lines and shade colors indicate geopotential height and potential temperature, respectively. The thick and dotted line indicates the isoline of 308K. Areas with altitude greater than $1500 \mathrm{~m}$ are shaded black. 
Figure 10: Time-series of outgoing long-wave radiation (OLR) over the west coast of the Indian subcontinent, $\theta_{I W}$, and $|\mathbf{U}|_{A}$ in 2001. The thick line, marked line, and broken line indicate OLR, $\theta_{I W}$, and $|\mathbf{U}|_{A}$ respectively.

Figure 11: Visible channel images of Meteosat for the period around the onset of the ISM in 2001.

Figure 12: Time-series of outgoing long-wave radiation (OLR) over the west coast of the Indian subcontinent, $\theta_{I W}$, and $|\mathbf{U}|_{A}$ in other non-cyclone-caused ISM onset cases. The thick line, marked line, and broken line indicate OLR, $\theta_{I W}$, and $|\mathbf{U}|_{A}$ respectively.

Figure 13: Results in a), c), e) and g) are horizontal distribution of the advection term $(-v \cdot \nabla T)$ of the temporal variation in air temperature, and b), d), f) and h) are the daily variation of air temperature, at $850 \mathrm{hPa}$ for the period before the ISM onset in 2001. The unit is K/day for both results. Areas shaded by light gray indicate negative values. Areas with altitude greater than 1500 $\mathrm{m}$ are shaded black.

Figure 14: Composite of the potential temperature, wind and geopotential height at 850hPa for a) cyclone-caused onset cases and b) non-cyclone-caused onset cases. Result in c) is the difference calculated by subtracting the non-cyclone-caused composite from the cyclone-caused one.

NCEP/NCAR reanalysis data are used. Contour lines and shade colors indicate geopotential height and potential temperature, respectively. The thick white line in c) indicates the isoline of $0 \mathrm{~K}$.

Areas with altitude greater than $1500 \mathrm{~m}$ are shaded black.

Table 1: ISM onset date defined in Taniguchi and Koike (2006) and the cause of the PT decrease.

\begin{tabular}{|l|l|l||l|l|l|}
\hline Year & Onset Date & $\begin{array}{l}\text { Cause of the } \\
\text { PT decrease }\end{array}$ & Year & Onset date & $\begin{array}{l}\text { Cause of the } \\
\text { PT decrease }\end{array}$ \\
\hline 1979 & Jun-16 & Non-Cyclone & 1992 & Jun-15 & Cyclone \\
\hline 1980 & Jun-3 & Non-Cyclone & 1993 & Jun-6 & Cyclone \\
\hline 1981 & Jun-17 & Non-Cyclone & 1994 & Jun-3 & Non-Cyclone \\
\hline 1982 & Jun9 & Cyclone & 1995 & Jun-10 & Non-Cyclone \\
\hline 1983 & Jun-16 & Cyclone & 1996 & Jun-9 & Cyclone \\
\hline 1984 & May-31 & Non-Cyclone & 1997 & Jun-16 & Cyclone \\
\hline 1985 & May27 & Cyclone & 1998 & Jun-7 & Cyclone \\
\hline 1986 & Jun-9 & Cyclone & 1999 & May-18 & Cyclone \\
\hline 1987 & Jun-4 & Cyclone & 2000 & May-14 & Non-Cyclone \\
\hline 1988 & Jun-9 & Non-Cyclone & 2001 & May-23 & Non-Cyclone \\
\hline 1989 & Jun-1 & Non-Cyclone & 2002 & Jun-11 & Cyclone \\
\hline 1990 & May-25 & Cyclone & 2003 & Jun-9 & Cyclone \\
\hline 1991 & Jun-6 & Cyclone & 2004 & Jun-6 & Non-Cyclone \\
\hline
\end{tabular}


40N $\theta \& U \& Z$ \& $@ 850 \mathrm{hPa}$ Clim. P22 (Ave. 16-20APR)
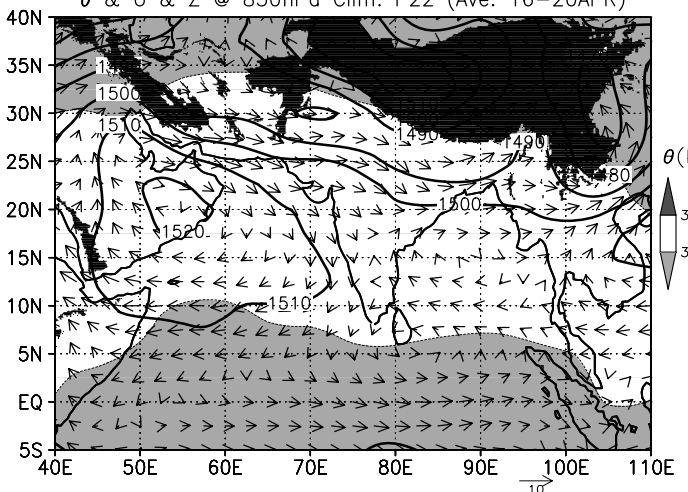

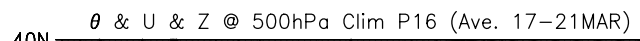

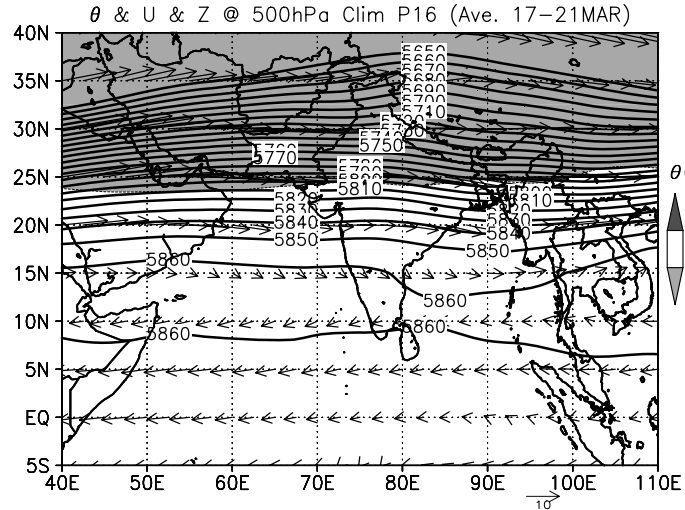

$\theta \& U \& Z$ \& 200hPa Clim. P16 (Ave. 17-21MAR)

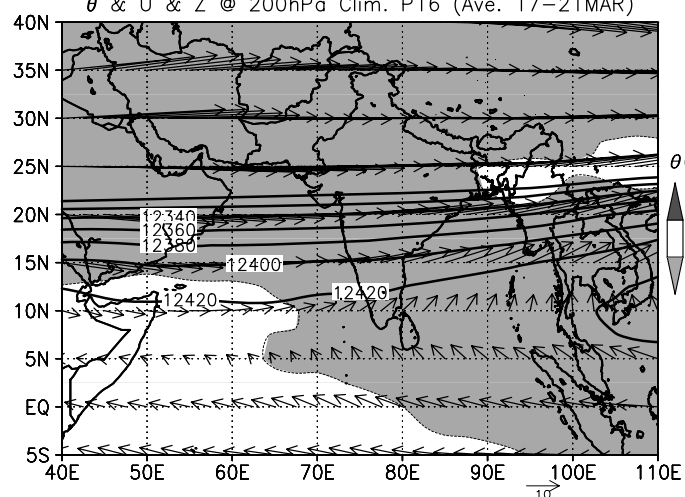

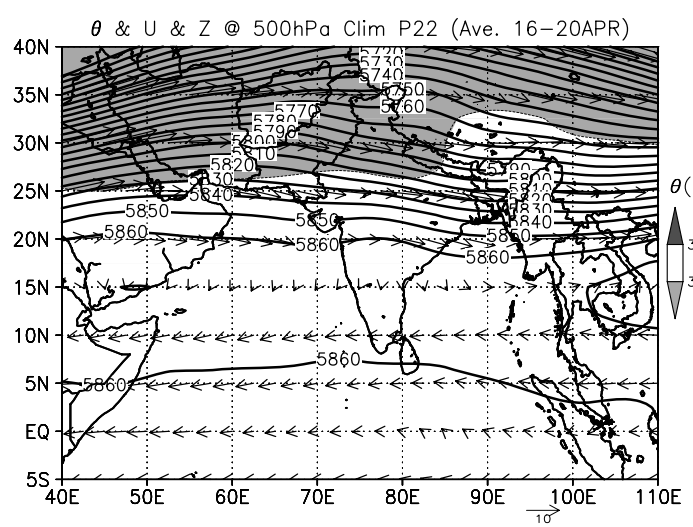

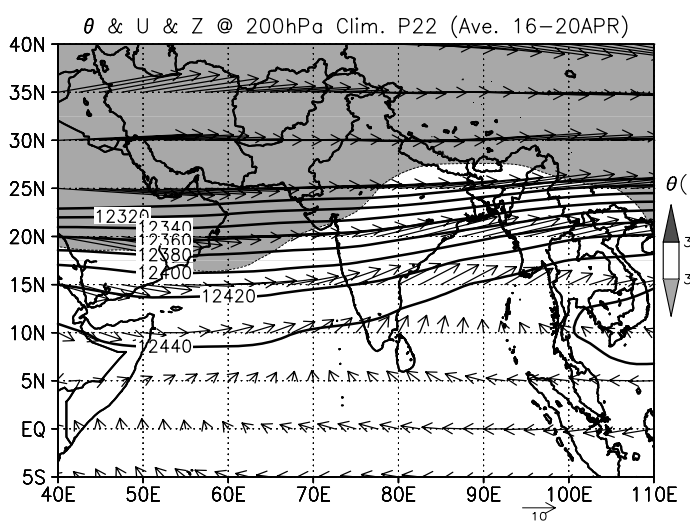

40N $\theta \& U \& Z$ \& $950 \mathrm{hPa}$ Clim. P26 (Ave. 06-10MAY)
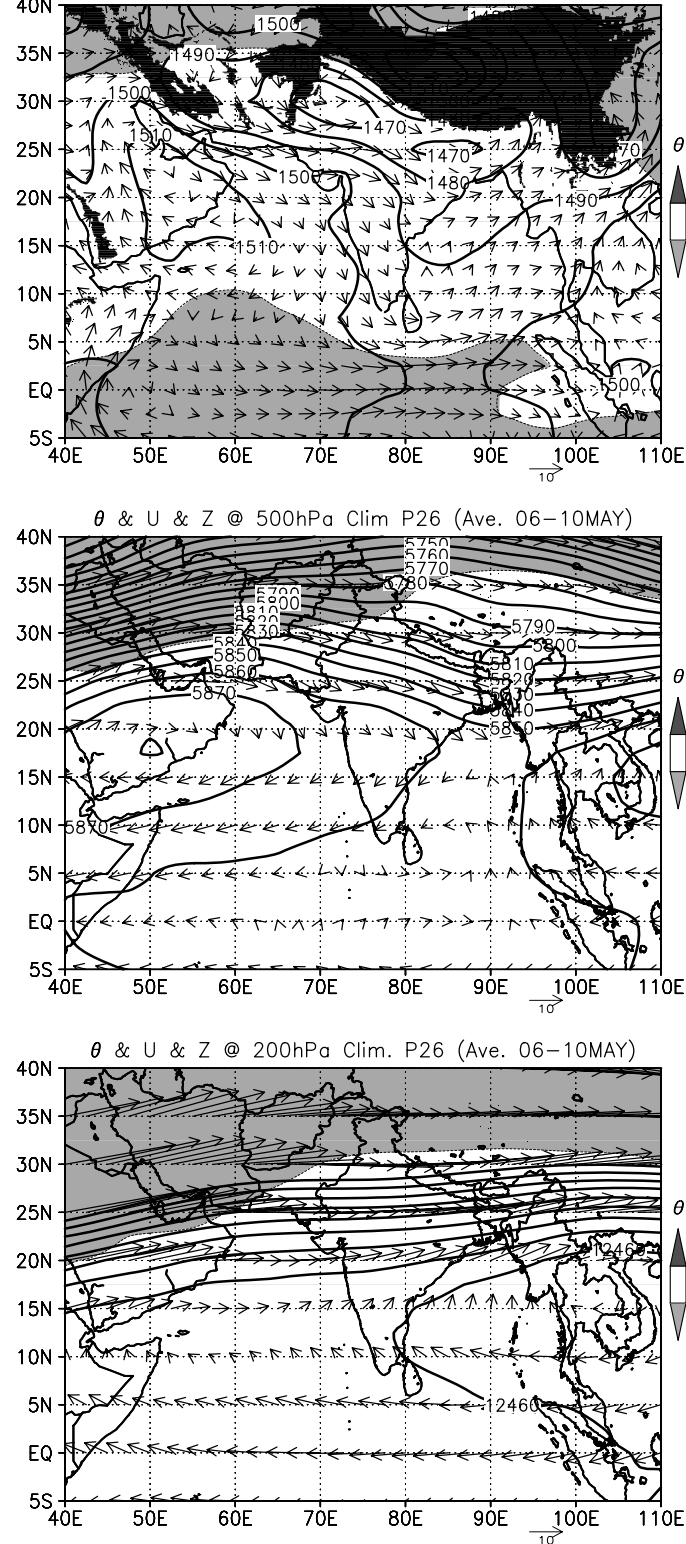


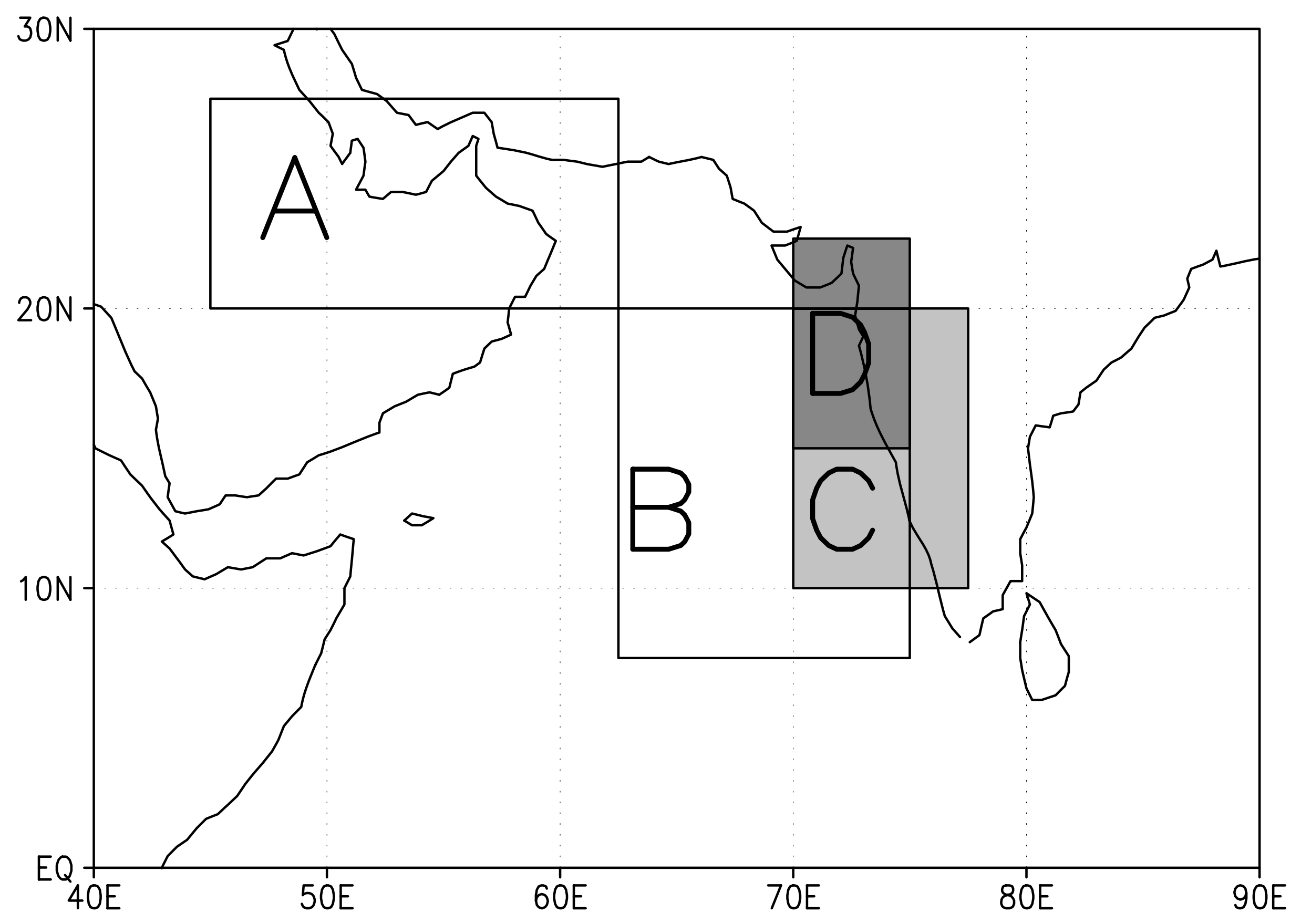


2004/05/04-09UTC

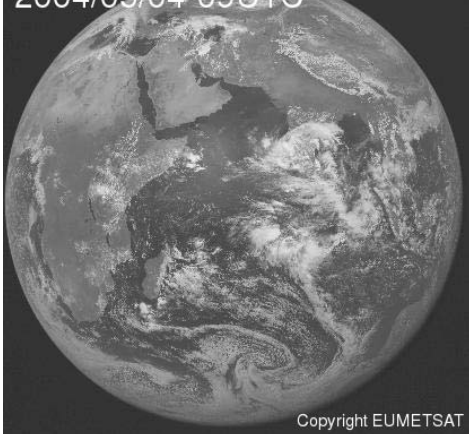

Copyright EUMETSAT

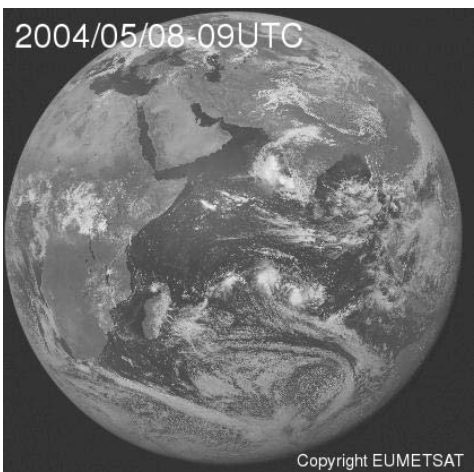

2004/05/05-09UTC
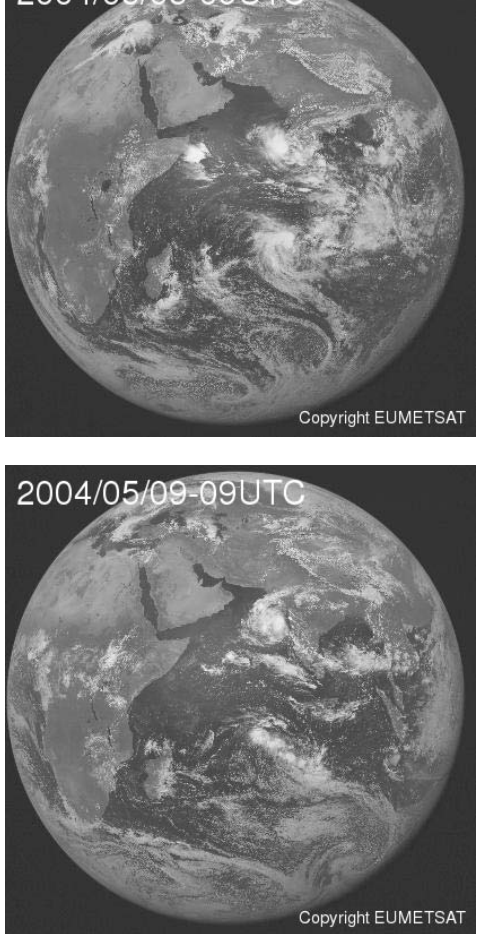

2004/05/06-09UTC

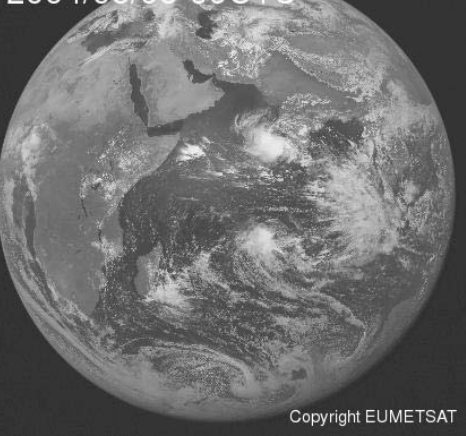

2004/05/10=09UTC

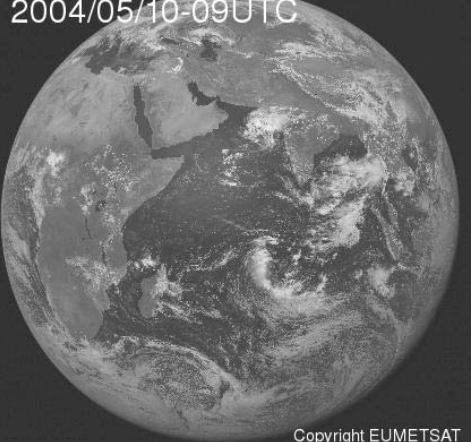

2004/05/07-09UTC

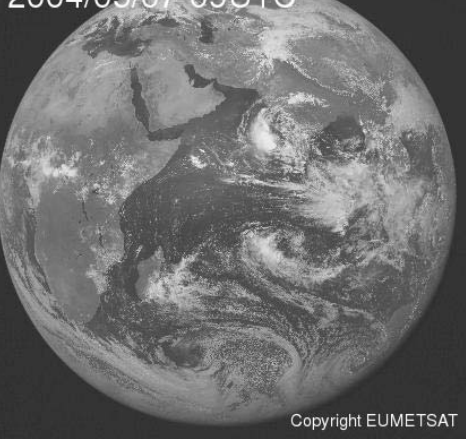

2004/05/11-09UTC

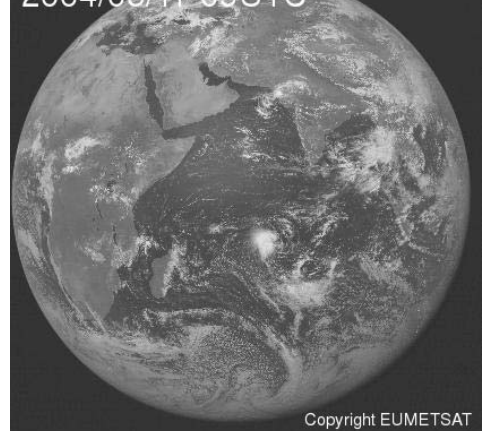


OLR

W-India OLR \& $\theta_{\mathrm{IW}} \&|U|_{\mathrm{A}} @ 850 \mathrm{hPa} 2001$

$|U|_{A}$

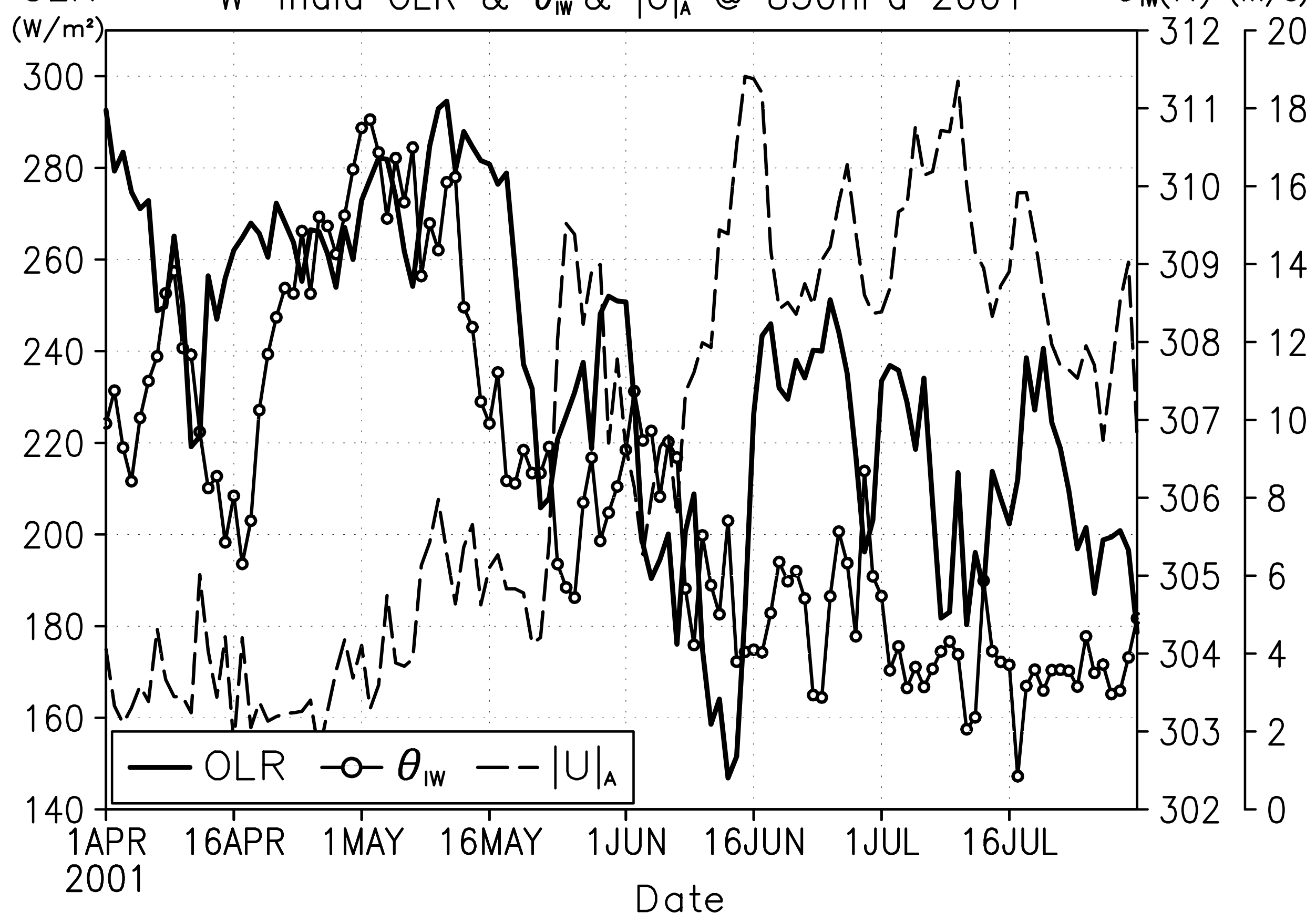


2001/05/09-09UTC

Copyright EUMETSAT

2001/05/12,09UTC

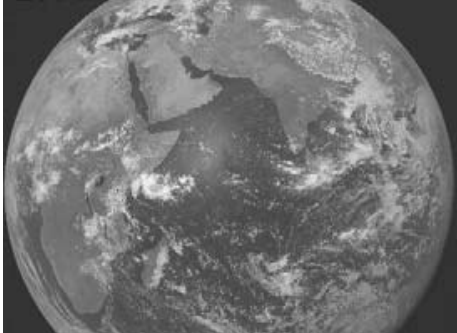

Copyright EUMETSAT

\section{1/05/15-098TC}

Copyright EUMETSAT

2001/05/18-09UTC

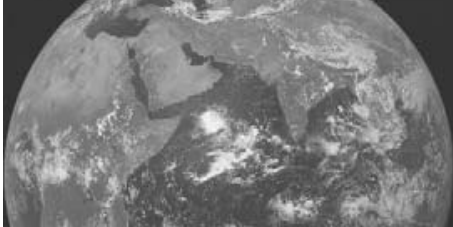

wher 203
2001/05/10-091/TC

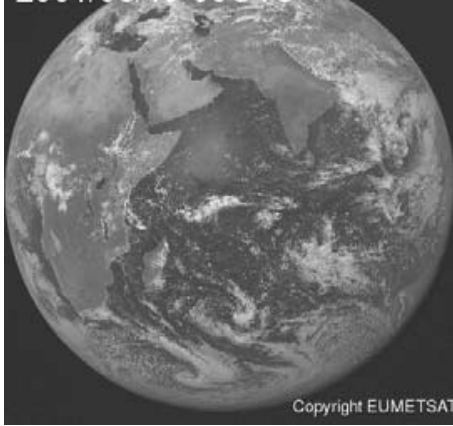

Copyright EUMETSAT

$2001 / 05 / 16-09$ UTC

Copyright EUMETSAT

2001/05/19-094TC

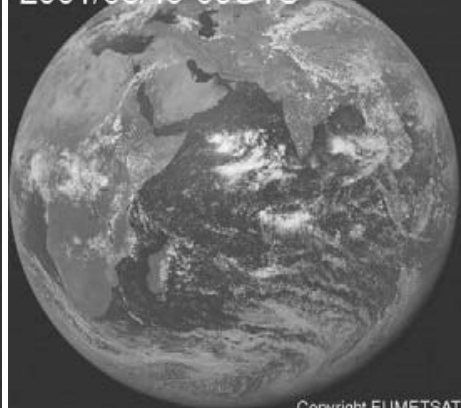

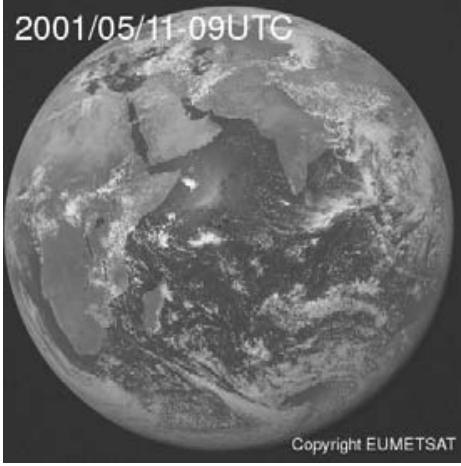

2001/05/14 09UTC

Copyright EUMETSAT

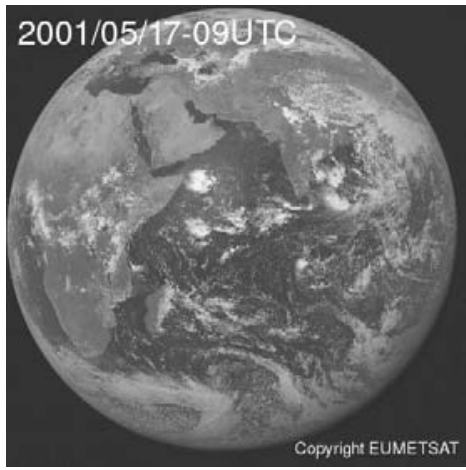

2001/05/20-09UTC

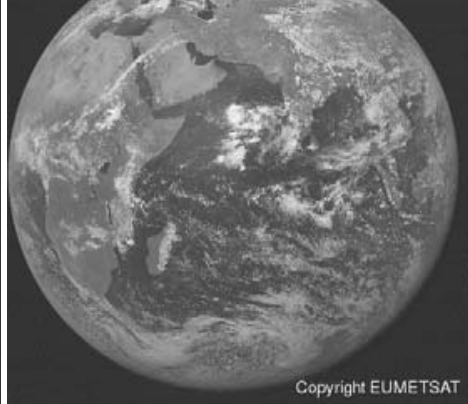




\section{a)}

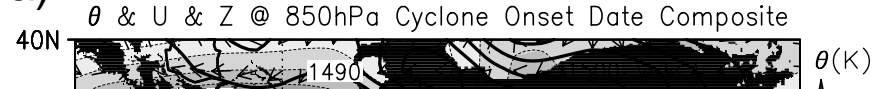

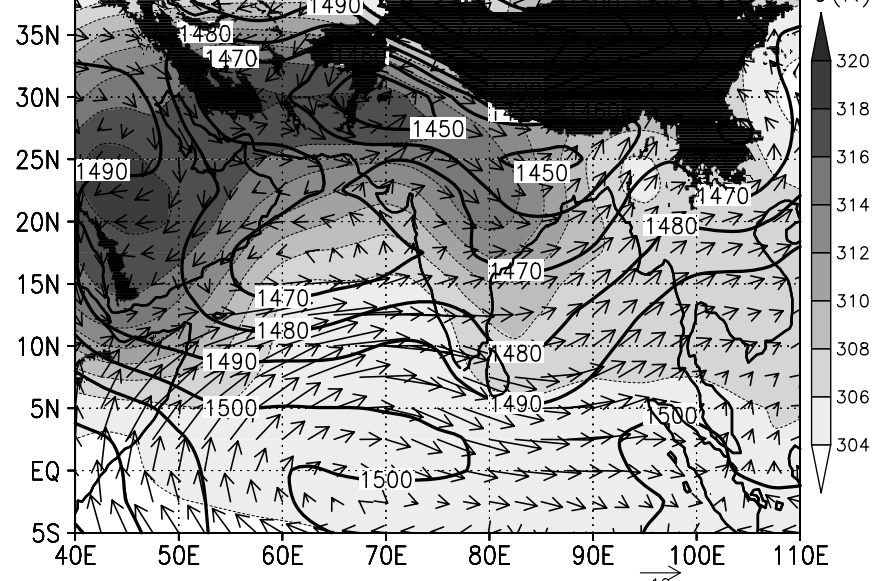

b)

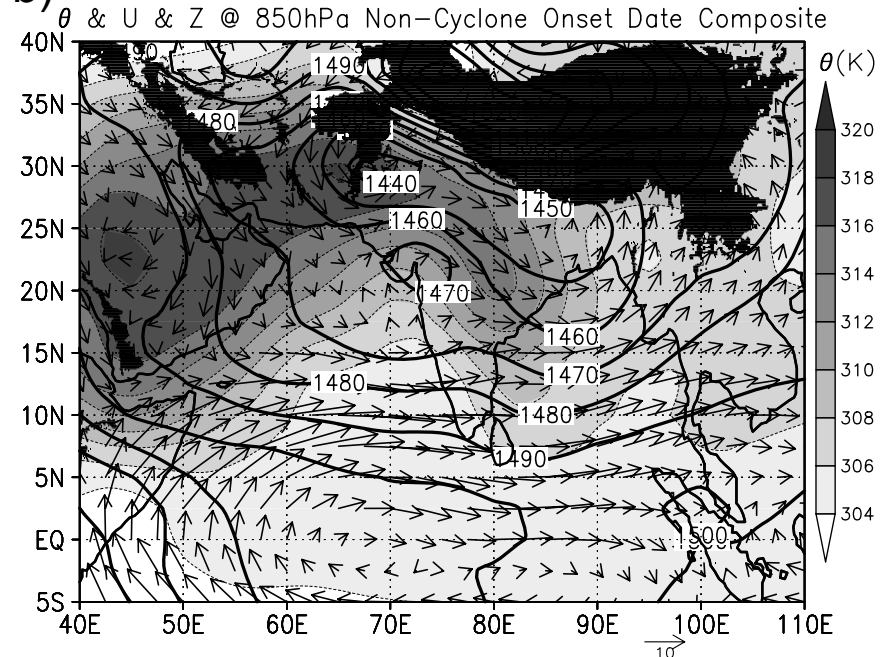

c)

Diff. of $\theta \& U \& Z @ 850 \mathrm{hPa}$

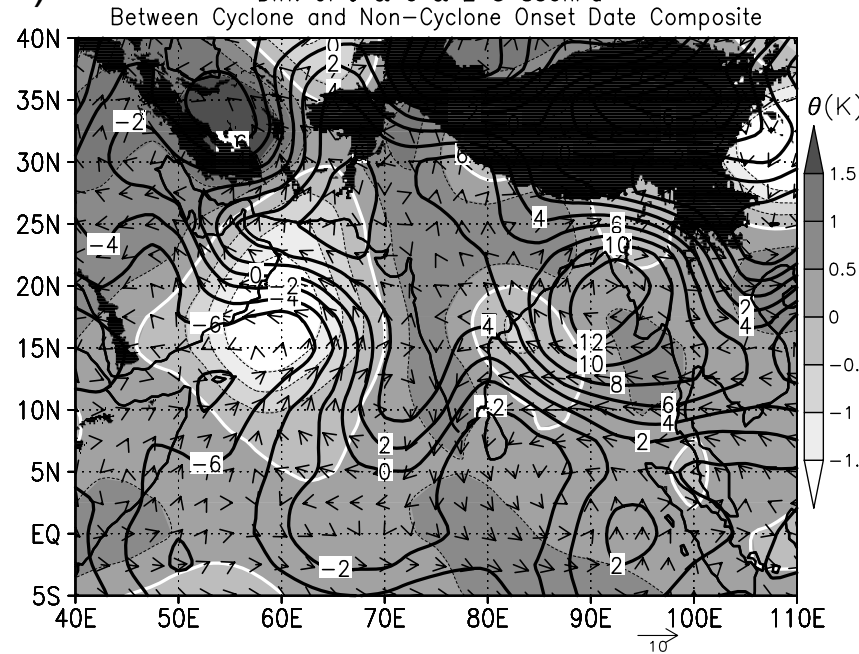

